\title{
Terbium-161 for PSMA-targeted radionuclide therapy of prostate cancer
}

\author{
Cristina Müller ${ }^{1}$ (D) Christoph A. Umbricht ${ }^{1} \cdot$ Nadezda Gracheva $^{1} \cdot$ Viviane J. Tschan $^{1} \cdot$ Giovanni Pellegrini $^{2}$. \\ Peter Bernhardt ${ }^{3}$. Jan Rijn Zeevaart ${ }^{4}$. Ulli Köster ${ }^{5} \cdot$ Roger Schibli ${ }^{1,6} \cdot$ Nicholas P. van der Meulen ${ }^{1,7}$
}

Received: 18 February 2019 / Accepted: 29 April 2019 / Published online: 27 May 2019

(C) The Author(s) 2019

\begin{abstract}
Purpose The prostate-specific membrane antigen (PSMA) has emerged as an interesting target for radionuclide therapy of metastasized castration-resistant prostate cancer (mCRPC). The aim of this study was to investigate ${ }^{161} \mathrm{~Tb}\left(\mathrm{~T}_{1 / 2}=6.89\right.$ days; $\mathrm{E} \beta_{\mathrm{av}}=154 \mathrm{keV}$ ) in combination with PSMA-617 as a potentially more effective therapeutic alternative to ${ }^{177}$ Lu-PSMA-617, due to the abundant co-emission of conversion and Auger electrons, resulting in an improved absorbed dose profile.

Methods ${ }^{161} \mathrm{~Tb}$ was used for the radiolabeling of PSMA-617 at high specific activities up to $100 \mathrm{MBq} / \mathrm{nmol} .{ }^{161} \mathrm{~Tb}-\mathrm{PSMA}-617$ was tested in vitro and in tumor-bearing mice to confirm equal properties, as previously determined for ${ }^{177}$ Lu-PSMA-617. The effects of ${ }^{161}$ Tb-PSMA-617 and ${ }^{177}$ Lu-PSMA-617 on cell viability (MTT assay) and survival (clonogenic assay) were compared in vitro using PSMA-positive PC-3 PIP tumor cells. ${ }^{161}$ Tb-PSMA-617 was further investigated in therapy studies using PC-3 PIP tumor-bearing mice.

Results ${ }^{161}$ Tb-PSMA-617 and ${ }^{177}$ Lu-PSMA-617 displayed equal in-vitro properties and tissue distribution profiles in tumorbearing mice. The viability and survival of PC-3 PIP tumor cells were more reduced when exposed to ${ }^{161} \mathrm{~Tb}-\mathrm{PSMA}-617$ as compared to the effect obtained with the same activities of ${ }^{177} \mathrm{Lu}$-PSMA-617 over the whole investigated concentration range. Treatment of mice with ${ }^{161} \mathrm{~Tb}-\mathrm{PSMA}-617(5.0 \mathrm{MBq} /$ mouse and $10 \mathrm{MBq} /$ mouse, respectively) resulted in an activity-dependent increase of the median survival ( 36 vs 65 days) compared to untreated control animals ( 19 days). Therapy studies to compare the effects of ${ }^{161} \mathrm{~Tb}$-PSMA-617 and ${ }^{177} \mathrm{Lu}$-PSMA-617 indicated the anticipated superiority of ${ }^{161} \mathrm{~Tb}$ over ${ }^{177} \mathrm{Lu}$.

Conclusion ${ }^{161} \mathrm{~Tb}$-PSMA-617 showed superior in-vitro and in-vivo results as compared to ${ }^{177} \mathrm{Lu}$-PSMA-617, confirming theoretical dose calculations that indicate an additive therapeutic effect of conversion and Auger electrons in the case of ${ }^{161} \mathrm{~Tb}$. These data warrant more preclinical research for in-depth investigations of the proposed concept, and present a basis for future clinical translation of ${ }^{161}$ Tb-PSMA-617 for the treatment of mCRPC.
\end{abstract}

Keywords ${ }^{161} \mathrm{~Tb} \cdot$ Auger electrons $\cdot$ Prostate cancer $\cdot$ PSMA ligands $\cdot$ Radioligand therapy

This article is part of the Topical Collection on Oncology - Genitourinary

Electronic supplementary material The online version of this article (https://doi.org/10.1007/s00259-019-04345-0) contains supplementary material, which is available to authorized users.

Cristina Müller

cristina.mueller@psi.ch

1 Center for Radiopharmaceutical Sciences ETH-PSI-USZ, Paul Scherrer Institute, 5232 Villigen, Switzerland

2 Laboratory for Animal Model Pathology, Institute of Veterinary Pathology, Vetsuisse Faculty, University of Zurich, 8057 Zurich, Switzerland

3 Department of Radiation Physics, Institution of Clinical Science, Sahlgrenska Academy, University of Gothenburg, 413 45 Gothenburg, Sweden
4 Radiochemistry, South African Nuclear Energy Corporation (Necsa), Brits 0240, South Africa

5 Institut Laue-Langevin, 38042 Grenoble, France

6 Department of Chemistry and Applied Biosciences, ETH Zurich, 8093 Zurich, Switzerland

7 Laboratory of Radiochemistry, Paul Scherrer Institute, 5232 Villigen, Switzerland 


\section{Introduction}

The prostate-specific membrane antigen (PSMA) is a cellsurface glycoprotein that is expressed in normal prostate tissue and overexpressed in prostate cancer [1,2]. There are indications that the expression level of PSMA correlates with the stage of the disease and the risk of disease progression [3, 4]. PSMA is, therefore, an interesting target to use for radionuclide therapy of metastasized castration-resistant prostate cancer (mCRPC) [5-8]. The topic of PSMA targeting became popular with the development of small-molecule-based radioligands [9]. Initial compounds were designed for radioiodination, suitable for nuclear imaging, and the first to be used therapeutically in patients [10]. Subsequently, PSMA ligands were developed with a chelator to allow their use in combination with radiometals for both imaging and therapeutic purposes $[5,8,11]$. PSMA-617 and PSMA I\&T, equipped with a DOTA and DOTAGA chelator, respectively, have been used for targeted radionuclide therapy of mCRPC in clinics [7, $12,13]$. For this purpose, they were mostly labeled with ${ }^{177} \mathrm{Lu}$ $\left(\mathrm{T}_{1 / 2}=6.65 \mathrm{~d} ; \mathrm{E} \beta_{\mathrm{av}}=134 \mathrm{keV} ; \mathrm{E} \gamma=113 \mathrm{keV}, \mathrm{I}=6.17 \%\right.$, $\mathrm{E} \gamma=208 \mathrm{keV}, \mathrm{I}=10.36 \%$ ), which is currently the mostoften applied radiometal for therapeutic purposes in the clinics [14]. In specific cases, ${ }^{225}$ Ac-PSMA-617 was employed for the treatment of patients at end-stage without further treatment options [15-17]. ${ }^{225} \mathrm{Ac}$ decays with a half-life of 10 days, emitting several $\alpha$ - and $\beta^{-}$-particles while decaying via a sequence of radioactive daughter nuclides [18]. Although the results obtained with ${ }^{225}$ Ac-PSMA-617 were impressive, undesired side effects - referring to irreversible damage of salivary and lacrimal glands - have been reported [17]. The question arises, therefore, whether alternative radiometals could be used for targeted radionuclide therapy of mCRPC which would be potentially more powerful than the currently-employed ${ }^{177} \mathrm{Lu}$, without causing additional sideeffects.

In this work, we investigated ${ }^{161} \mathrm{~Tb}$, a recently-introduced radiolanthanide for therapeutic applications [19]. ${ }^{161} \mathrm{~Tb}$ decays with a half-life of 6.89 days to stable ${ }^{161}$ Dy, while emitting $\beta^{-}$-particles $\left(\mathrm{E} \beta_{\mathrm{av}}=154 \mathrm{keV}\right)$ suitable for therapeutic purposes and $\gamma$-radiation $(\mathrm{E} \gamma=49 \mathrm{keV}, \mathrm{I}=17.0 \%$; $\mathrm{E} \gamma=$ $75 \mathrm{keV}, \mathrm{I}=10.2 \%$ ) useful for SPECT imaging. In this regard, ${ }^{161} \mathrm{~Tb}$ closely resembles ${ }^{177} \mathrm{Lu}$, even though the emitted $\gamma$ radiation is of lower energy. ${ }^{161} \mathrm{~Tb}$ also emits a substantial number of low-energy conversion and Auger electrons, which makes this radionuclide exceptionally interesting for the treatment of disseminated cancers with multiple metastases ranging from a single cell (diameter: $\sim 10 \mu \mathrm{m}$ ) to micro cell clusters (diameter: $<1 \mathrm{~mm}$ ) [20]. Monte Carlo simulations performed by Hindié et al. to assess the dose delivered to $10-\mu \mathrm{m}$ spheres revealed a 3.5 -fold increased value when using ${ }^{161} \mathrm{~Tb}$ as compared to ${ }^{177} \mathrm{Lu}$ [21]. In larger tumors (diameter $>10 \mathrm{~mm}$ ), the emitted electron energy from ${ }^{161} \mathrm{~Tb}$ and ${ }^{177} \mathrm{Lu}$ respectively is almost entirely absorbed, resulting in a 1.3-fold higher absorbed electron energy fraction per decay for ${ }^{161} \mathrm{~Tb}$ (total electron emission of $197 \mathrm{keV} /$ decay) compared to ${ }^{177} \mathrm{Lu}$ (147 keV/decay), making ${ }^{161} \mathrm{~Tb}$ more potent than ${ }^{177} \mathrm{Lu}[21]$. An additional advantage of ${ }^{161} \mathrm{~Tb}$ over ${ }^{177} \mathrm{Lu}$ may be the existence of diagnostic counterparts, including ${ }^{152} \mathrm{~Tb}\left(\mathrm{~T}_{1 / 2}=\right.$ $\left.17.5 \mathrm{~h} ; \mathrm{E} \beta^{+}{ }_{\mathrm{av}}=1140 \mathrm{keV}, \mathrm{I}=20.3 \%\right)$ and ${ }^{155} \mathrm{~Tb}\left(\mathrm{~T}_{1 / 2}=5.32\right.$ $\mathrm{d} ; \mathrm{E} \gamma=87 \mathrm{keV}, 32.0 \%, 105 \mathrm{keV}, \mathrm{I}=25.1 \%$ ) for PET and SPECT imaging respectively, potentially enabling pretherapeutic dosimetry with chemically identical radiopharmaceuticals [22-25]. The results of theoretical calculations performed by Champion and co-workers also indicate that ${ }^{161} \mathrm{~Tb}$ outperforms other clinically employed $\left({ }^{177} \mathrm{Lu},{ }^{90} \mathrm{Y}\right)$ and nonstandard therapeutic radionuclides $\left({ }^{47} \mathrm{Sc},{ }^{67} \mathrm{Cu}\right)$ with regard to the dose delivery to small lesions $[21,26]$.

The production of ${ }^{161} \mathrm{~Tb}$ via the ${ }^{160} \mathrm{Gd}(\mathrm{n}, \gamma){ }^{161} \mathrm{Gd} \rightarrow{ }^{161} \mathrm{~Tb}$ nuclear reaction was previously reported by Lehenberger et al. [19]. At the Paul Scherrer Institute (PSI), the method of processing Gd targets irradiated in high neutron flux reactors (RHF, Institut Laue-Langevin, Grenoble, France or SAFARI-1, Necsa, Pelindaba, South Africa) or at a spallation neutron source (SINQ, PSI, Switzerland) was implemented some years ago [22]. The chemical separation of ${ }^{161} \mathrm{~Tb}$ from the target material has since been further developed and optimized at PSI.

The topic of the present study was to investigate ${ }^{161} \mathrm{~Tb}$ with regard to its application for radionuclide therapy. ${ }^{161} \mathrm{~Tb}$ was, therefore, used to label PSMA-617 to enable preclinical comparison with ${ }^{177} \mathrm{Lu}$-PSMA-617. The in-vitro experiments and biodistribution studies in PC-3 PIP/flu tumor-bearing mice were performed to confirm equal chemical and pharmacokinetic properties of ${ }^{161} \mathrm{~Tb}$-PSMA-617 and ${ }^{177} \mathrm{Lu}$-PSMA-617 respectively. Importantly, the effect of ${ }^{161}$ Tb-PSMA-617 was compared to that obtained with ${ }^{177}$ Lu-PSMA- 617 by means of in-vitro cell viability and survival assays, and the therapeutic effect of ${ }^{161}$ Tb-PSMA-617 was shown in vivo using tumorbearing mice.

\section{Materials and methods}

\section{Production and chemical separation of ${ }^{161} \mathrm{~Tb}$}

${ }^{161} \mathrm{~Tb}$ was produced as previously reported [22]. Enriched ${ }^{160} \mathrm{Gd}$ targets were irradiated over a period of $1-2$ weeks at the SAFARI-1 reactor at Necsa, Pelindaba, South Africa, or at the RHF at Institut Laue-Langevin, Grenoble, France. In some cases, 3-week irradiations were performed at the spallation-induced neutron source SINQ, PSI, Switzerland. ${ }^{161} \mathrm{~Tb}$ was chemically separated from the Gd target material and impurities by cation exchange chromatography, using an optimized method of the previously-published process (Supplementary Material) [19, 22]. 


\section{Preparation and in-vitro evaluation of ${ }^{161} \mathrm{~Tb}-\mathrm{PSMA}-617$}

The radiolabeling of PSMA-617 (Advanced Biochemical Compounds, ABX GmbH, Radeberg, Germany) with ${ }^{161} \mathrm{~Tb}$ was performed under standard labeling conditions (Supplementary material). The stability of ${ }^{161} \mathrm{~Tb}$-PSMA-617, incubated in saline $(250 \mathrm{MBq} / 500 \mu \mathrm{L})$, was investigated over a period of $24 \mathrm{~h}$ at room temperature (Supplementary material). The $n$-octanol/PBS distribution coefficient $(\log D)$ was determined for ${ }^{161} \mathrm{~Tb}$-PSMA-617 (Supplementary material). All of these experiments were performed as previously reported for ${ }^{177}$ Lu-PSMA-617 [27].

\section{Tumor cell uptake and internalization studies}

Uptake and internalization studies of ${ }^{161}$ Tb-PSMA-617 and ${ }^{177} \mathrm{Lu}$-PSMA-617 were performed, as previously reported, using PSMA-positive PC-3 PIP and PSMA-negative PC-3 flu tumor cells (provided by Prof. Dr. Martin Pomper; John Hopkins University, Baltimore, USA) (Supplementary material) [27].

\section{Cell viability assay (MTT assay) and cell survival assay (clonogenic assay)}

Tumor cell viability of PC-3 PIP/flu tumor cells upon exposure to ${ }^{161} \mathrm{~Tb}$-PSMA-617 and ${ }^{177} \mathrm{Lu}-\mathrm{PSMA}-617$ (0.01$20 \mathrm{MBq} / \mathrm{mL}$ ) was assessed using a 3-(4,5-dimethylthiazol-2yl)-2,5-diphenyltetrazolium bromide (MTT) assay, as described by Mosmann [28], and performed according to a previously-reported procedure [29]. The survival of PC-3 PIP/flu tumor cells upon exposure to ${ }^{161} \mathrm{~Tb}-\mathrm{PSMA}-617$ and ${ }^{177}$ Lu-PSMA-617 (0.01-10 MBq/mL) was determined using the clonogenic assay, as described by Franken et al. [30], and performed according to a previously-reported procedure [31]. The detailed methods of these studies, including dosimetric calculations, are described in the Supplementary material. The results were analyzed for statistical significance by a two-way ANOVA with Sidak's multiple comparison post-test using Graph Pad Prism (version 7).

\section{In-vivo studies}

In-vivo experiments were approved by the local veterinarian department and conducted in accordance with the Swiss law of animal protection. Athymic nude BALB/c mice were obtained from Charles River Laboratories (Sulzfeld, Germany) at the age of 5-6 weeks. Mice were subcutaneously inoculated with PC-3 PIP tumor cells $\left(6 \times 10^{6}\right.$ cells in $100 \mu \mathrm{L}$ Hank's balanced salt solution (HBSS) with $\mathrm{Ca}^{2+} / \mathrm{Mg}^{2+}$ ) and PSMAnegative PC-3 flu tumor cells $\left(5 \times 10^{6}\right.$ cells in $100 \mu \mathrm{L}$ HBSS with $\left.\mathrm{Ca}^{2+} / \mathrm{Mg}^{2+}\right)$ on the right and left shoulder, respectively, for biodistribution and SPECT imaging studies. Therapy studies were performed with mice inoculated with PC-3 PIP cells $\left(4 \times 10^{6}\right.$ cells in HBSS with $\left.\mathrm{Ca}^{2+} / \mathrm{Mg}^{2+}\right)$ on the right shoulder (Supplementary material).

\section{Biodistribution studies}

Biodistribution studies were performed 12-14 days after tumor cell inoculation when the tumor xenografts reached an average tumor volume of about $\sim 50-200 \mathrm{~mm}^{3}$ (Supplementary material). PSMA-617 was labeled with ${ }^{161} \mathrm{~Tb}$ at a specific activity of $5.0 \mathrm{MBq} / \mathrm{nmol}$ and diluted in saline. Tumor-bearing mice were intravenously injected with ${ }^{161}$ Tb-PSMA-617 (5.0 MBq, $\left.1 \mathrm{nmol}, 100 \mu \mathrm{L}\right)$. The mice were sacrificed at $1 \mathrm{~h}, 4 \mathrm{~h}, 24 \mathrm{~h}, 48 \mathrm{~h}$, or $96 \mathrm{~h}$ post injection (p.i.) and selected tissues and organs were collected, weighed, and measured using a $\gamma$-counter (Perkin Elmer, Wallac Wizard 1480). Groups of 3-5 mice were sacrificed at each time point. The results were decay-corrected and listed as percentage of the injected activity per gram of tissue mass (\% IA/g). Data are presented as the average \pm standard deviation (SD).

The data were compared with those previously obtained for ${ }^{177}$ Lu-PSMA-617 [27] and analyzed for significance using a one-way ANOVA with Tukey's multiple comparison post-test using GraphPad Prism software (version 7). A $p$-value of $<0.05$ was considered statistically significant.

\section{Dosimetry estimations}

The mean specific absorbed doses (Gy/MBq) to the tumor xenografts and the kidneys were estimated for ${ }^{161}$ Tb-PSMA617 and ${ }^{177}$ Lu-PSMA-617 (Supplementary material). The tissue distribution profile of ${ }^{161}$ Tb-PSMA-617 was considered as equal to the previously-determined biodistribution data of ${ }^{177} \mathrm{Lu}-\mathrm{PSMA}-617$ [27, 32]. The [\% IA/g] values were converted to non-decay corrected values using the respective halflives of the radionuclides to obtain time-integrated activity to infinity. The mean absorbed energy per decay to cells in the cell viability study was calculated using Monte Carlo simulations with PENELOPE-2014 [33].

\section{SPECT/CT imaging studies}

In a separate study, SPECT/CT experiments were performed 12-14 days after tumor cell inoculation using a dedicated small-animal SPECT/CT camera (NanoSPECT/ $\mathrm{CT}^{\mathrm{TM}}$, Mediso Medical Imaging Systems, Budapest, Hungary) as previously reported (Supplementary material) [34]. ${ }^{161}$ Tb-PSMA-617 ( 25 MBq/nmol) was diluted in saline for injection. Scans were acquired at $1 \mathrm{~h}, 4 \mathrm{~h}$, and $24 \mathrm{~h}$ after injection of the radioligands $(\sim 25 \mathrm{MBq}$, $1 \mathrm{nmol}, 100 \mu \mathrm{L}$ ). During the in-vivo scans, mice were anesthetized using a mixture of Isoflurane and oxygen. 


\section{Therapy study}

Three groups of mice $(n=6)$ were injected with only saline, ${ }^{161} \mathrm{~Tb}-\mathrm{PSMA}-617$ (5.0 MBq; $\left.1 \mathrm{nmol} / \mathrm{mouse}\right)$, or ${ }^{161} \mathrm{~Tb}-\mathrm{PSMA}-617$ (10 MBq; $\left.1 \mathrm{nmol} / \mathrm{mouse}\right)$ at Day 0 of the therapy, 6 days after PC-3 PIP tumor cell inoculation (Table 1). The mice were monitored by measuring body weights and the tumor sizes every other day over 12 weeks. Mice were euthanized when pre-defined endpoint criteria were reached, or when the study was terminated at Day 84 (Supplementary material). The relative body weight $(\mathrm{RBW})$ was defined as $\left[\mathrm{BW}_{\mathrm{x}} / \mathrm{BW}_{0}\right]$, where $\mathrm{BW}_{\mathrm{x}}$ is the body weight in gram at a given day $\mathrm{x}$, and $\mathrm{BW}_{0}$ the body weight in grams at Day 0 . The tumor dimension was determined by measuring the longest tumor axis (L) and its perpendicular axis (W) with a digital caliper. The tumor volume (V) was calculated according to the eq. $\left[\mathrm{V}=0.5 *\left(\mathrm{~L} * \mathrm{~W}^{2}\right)\right]$. The relative tumor volume (RTV) was defined as $\left[\mathrm{TV}_{\mathrm{x}} / \mathrm{TV}_{0}\right]$, where $\mathrm{TV}_{\mathrm{x}}$ is the tumor volume in $\mathrm{mm}^{3}$ at a given day $\mathrm{x}$, and $\mathrm{TV}_{0}$ the tumor volume in $\mathrm{mm}^{3}$ at Day 0 .

\section{Assessment of therapy study}

The efficacy of the radionuclide therapy was assessed by the tumor growth delay $\left(\mathrm{TGD}_{\mathrm{x}}\right)$, which was calculated as the time required for the tumor volume to increase $\mathrm{x}$-fold over the initial volume at Day 0. The tumor growth delay index $\left[\mathrm{TGDI}_{\mathrm{x}}=\mathrm{TGD}_{\mathrm{x}}(\mathrm{T}) / \mathrm{TGD}_{\mathrm{x}}(\mathrm{C})\right]$ was calculated as the $\mathrm{TGD}_{\mathrm{x}}$ ratio of treated mice $(\mathrm{T})$ over control mice $(\mathrm{C})$ for a 2-fold $\left(\mathrm{x}=2, \mathrm{TGD}_{2}\right)$ and 5 -fold $\left(\mathrm{x}=5, \mathrm{TGD}_{5}\right)$ increase of the initial tumor volume. Statistical analysis was performed by a one-way ANOVA with Tukey's multiple comparison post-test using GraphPad Prism software (version 7). A value of $p<0.05$ was considered statistically significant. The median survival was calculated by Kaplan-Meier curves using GraphPad Prism software (version 7).
Potential early side-effects related to the exposure to radiation were evaluated by the assessment of absolute and relative (to body and to brain) organ weights, selected clinical chemistry plasma parameters including creatinine (CRE), blood urea nitrogen (BUN), alkaline phosphatase (ALP), total bilirubin (TBIL), and albumin (ALB), as well as via histological analysis of bone marrow and salivary glands. The data were analyzed for statistical significance (Supplementary material).

\section{Additional in-vivo investigations using ${ }^{161}$ Tb-PSMA-617}

Additional investigations performed in mice that received ${ }^{161}$ Tb-PSMA-617 or ${ }^{177}$ Lu-PSMA-617 (2.5 MBq/mouse, 5.0 MBq/mouse or $10 \mathrm{MBq} /$ mouse) 2 days after PC-3 PIP tumor cell inoculation are reported in the Supplementary material.

\section{Results}

\section{Production of ${ }^{161} \mathrm{~Tb}$}

No-carrier-added ${ }^{161} \mathrm{~Tb}$ was produced at high activities of 6$20 \mathrm{GBq}$ (end of irradiation) depending on the irradiation parameters (neutron flux, irradiation time, and mass of target material). The chemical separation resulted in a radionuclidically pure $\left({ }^{160} \mathrm{~Tb}<0.007 \%\right)$ product of high radiochemical purity comparable to commercial, no-carrieradded ${ }^{177} \mathrm{Lu}$ (Supplementary material, Table S1). ${ }^{161} \mathrm{~Tb}$ was made available at a high-activity concentration (10-20 MBq/ $\mu \mathrm{L})$ in Suprapur ${ }^{\mathrm{TM}} \mathrm{HCl}(0.05 \mathrm{M})$ to be used directly for radiolabeling of PSMA-617.

\section{Radiolabeling, stability and in-vitro properties}

Radiolabeling of PSMA-617 with ${ }^{161} \mathrm{~Tb}$ was achieved at specific activities up to $100 \mathrm{MBq} / \mathrm{nmol}$ at a radiochemical purity

Table 1 Design of the tumor therapy study

\begin{tabular}{lllll}
\hline Treatment groups $(n=6)$ & Injected activity ${ }^{1}$ & $\begin{array}{l}\text { Calculated absorbed } \\
\text { dose to tumors }\end{array}$ & $\begin{array}{l}\text { Tumor volume } \\
\text { Day 0 }\end{array}$ & $\begin{array}{l}\text { Body weight } \\
\text { Day 0 }\end{array}$ \\
\hline & $(\mathrm{MBq})$ & $(\mathrm{Gy})$ & $\left(\mathrm{mm}^{3}\right)$ & $80 \pm 17$ \\
Saline & - & - & $74 \pm 28$ & $17 \pm 0.4$ \\
${ }^{161}$ Tb-PSMA-617 & 5.0 & 27 & $88 \pm 27$ & $17 \pm 1.2$ \\
${ }^{161}$ Tb-PSMA-617 & 10 & 54 & $(\mathrm{~g})$ & $1.0^{*}$ \\
\hline
\end{tabular}

${ }^{1}$ The quantity of activity of the injection solutions for each group was confirmed by counting an injection sample (100 $\left.\mu \mathrm{L}\right)$ using the dose calibrator.

* The average body weight of mice injected with $10 \mathrm{MBq}{ }^{161} \mathrm{~Tb}$-PSMA- 617 was significantly higher than the average body weight of mice injected with $5.0 \mathrm{MBq}^{161}$ Tb-PSMA-617 $(p<0.05)$. 
of $\geq 98 \%$ (Supplementary material, Fig. S1). ${ }^{161}$ Tb-PSMA$617(50 \mathrm{MBq} / \mathrm{nmol} ; 250 \mathrm{MBq} / 500 \mu \mathrm{L})$ was stable over at least $1 \mathrm{~h}(>98 \%)$, but showed radiolytic degradation when incubated for longer time periods. In the presence of L-ascorbic acid, ${ }^{161}$ Tb-PSMA-617 was stable up to $24 \mathrm{~h}(\geq 98 \%)$ and did not show any signs of radiolytic degradation (Supplementary material, Fig. S2). The determination of the $n$-octanol/PBS distribution coefficient ( $\log \mathrm{D}$ value) of ${ }^{161} \mathrm{~Tb}$ PSMA-617 resulted in a value of $-3.9 \pm 0.1$ (Supplementary material).

\section{Internalization studies}

The PC-3 PIP tumor cell uptake of ${ }^{161}$ Tb-PSMA-617 (47$54 \%)$ and the internalized fraction (8-11\%) after 2-4 h incubation was comparable to the data obtained with ${ }^{177} \mathrm{Lu}-$ PSMA-617 (49-58\% and 9-12\%, respectively). The uptake in PC-3 flu tumor cells was $<0.5 \%$ for both ${ }^{161}$ Tb-PSMA-617 and ${ }^{177}$ Lu-PSMA-617, respectively (Supplementary material, Fig. S3).

\section{In-vitro tumor-cell viability and survival}

The reduction of viability and survival of PC-3 PIP tumor cells after exposure to ${ }^{161} \mathrm{~Tb}$-PSMA-617 and ${ }^{177} \mathrm{Lu}$-PSMA-617 correlated with the applied activity concentration. ${ }^{161} \mathrm{~Tb}$ PSMA-617 was significantly more effective in reducing the tumor-cell viability (determined by MTT assays) and survival (determined by clonogenic assays) as compared to ${ }^{177} \mathrm{Lu}$ PSMA-617 when applied at activity concentrations in the range of $0.1-10 \mathrm{MBq} / \mathrm{mL}(p<0.05)$ and $0.05-5.0 \mathrm{MBq} / \mathrm{mL}$ $(p<0.05)$ respectively (Fig. 1a/b). Under the given experimental conditions, the mean absorbed energy to tumor cells in MTT assays was calculated to be 3.2-4.2-fold higher for ${ }^{161} \mathrm{~Tb}$ than for ${ }^{177} \mathrm{Lu}$. Lower values reflect the situation for cell monolayers, whereas the higher value refers to the "single-cell situation" which was more the case during the treatment, particularly in the setting of the clonogenic assay where the cell number per well was low. The viability of PSMA-negative PC-3 flu cells was not affected when the radioligands were applied at concentrations of up to $10 \mathrm{MBq} / \mathrm{mL}$. Only a slight reduction that was equal for both radioligands $(p>0.05)$ was detected at the highest concentration $(20 \mathrm{MBq} / \mathrm{mL})$. The survival of PC-3 flu cells was, however, affected at radioligand concentrations of $1 \mathrm{MBq} / \mathrm{mL}$ and higher, with a tendency of a more pronounced effect from ${ }^{161}$ Tb-PSMA-617 $(p>0.05)$ (Fig. $1 \mathrm{c} / \mathrm{d})$. The viability and survival of PC-3 PIP tumor cells exposed to ${ }^{161} \mathrm{~Tb}$-DPTA and ${ }^{177} \mathrm{Lu}$-DTPA were not affected, and showed only a marginal reduction at higher radioligand concentration, which was equal for both radionuclide complexes $(p>0.05)$ (Fig. 1e/f).

\section{Biodistribution studies and dose estimation}

Time-dependent biodistribution of ${ }^{161} \mathrm{~Tb}$-PSMA-617 was assessed in PC-3 PIP/flu tumor-bearing mice and compared to the data previously obtained with ${ }^{177} \mathrm{Lu}-\mathrm{PSMA}-617$ (Supplementary material, Table S2) [27, 32]. The uptake of ${ }^{161}$ Tb-PSMA-617 in PC-3 PIP tumor xenografts reached a maximum at 4 h p.i. $(49 \pm 5.5 \% \mathrm{IA} / \mathrm{g})$ and decreased slowly over time $(22 \pm 4.3 \% \mathrm{IA} / \mathrm{g}$ at $96 \mathrm{~h}$ p.i.). Accumulation of ${ }^{161}$ Tb-PSMA-617 in PC-3 flu tumors and other non-targeted organs was in the range of blood activity levels or below at any evaluated time point. The radioligand was cleared via the kidneys over the first few hours after injection $(9.6 \pm 1.3 \% \mathrm{IA} /$ g; 1 h p.i. $2.9 \pm 0.14 \% \mathrm{IA} / \mathrm{g} ; 4 \mathrm{~h}$ p.i.). These results confirmed that the tissue distribution profile of ${ }^{161} \mathrm{~Tb}$-PSMA-617 was equal $(p>0.05)$ to the data previously published for ${ }^{177} \mathrm{Lu}-$ PSMA-617 (Fig. 2) [27, 32].

For the absorbed dose estimations, the absorbed fractions of the assumed spherical tumors $\left(80 \mathrm{~mm}^{3}\right)$ were almost equal, with 0.96 and 0.93 for ${ }^{161} \mathrm{~Tb}$ and ${ }^{177} \mathrm{Lu}$ respectively. The estimated mean specific absorbed dose to the PC-3 PIP tumors was $5.34 \mathrm{~Gy} / \mathrm{MBq}$ and $3.90 \mathrm{~Gy} / \mathrm{MBq}$ for ${ }^{161} \mathrm{~Tb}-\mathrm{PSMA}-617$ and ${ }^{177} \mathrm{Lu}$-PSMA-617 respectively. This resulted in $27 \mathrm{~Gy}$ (5.0 MBq/mouse) and $53 \mathrm{~Gy}(10 \mathrm{MBq} / \mathrm{mouse})$ in mice treated with ${ }^{161} \mathrm{~Tb}-\mathrm{PSMA}-617$, and would result in $20 \mathrm{~Gy}$ (5.0 MBq/ mouse) and $39 \mathrm{~Gy}(10 \mathrm{MBq} /$ mouse $)$ if mice were treated with ${ }^{177} \mathrm{Lu}-\mathrm{PSMA}-617$. The mean specific absorbed dose to the kidneys for ${ }^{161} \mathrm{~Tb}$ and ${ }^{177} \mathrm{Lu}$ was determined as $0.062 \mathrm{~Gy} /$ $\mathrm{MBq}$ and $0.045 \mathrm{~Gy} / \mathrm{MBq}$ respectively, resulting in $0.31 \mathrm{~Gy}$ (5.0 MBq/mouse) and $0.62 \mathrm{~Gy}(10 \mathrm{MBq} /$ mouse $)$ in mice treated with ${ }^{161}$ Tb-PSMA-617. Should ${ }^{177}$ Lu-PSMA-617 be used, it would result in a kidney dose of $0.225 \mathrm{~Gy}$ (5.0 MBq/mouse) and $0.45 \mathrm{~Gy}(10 \mathrm{MBq} /$ mouse) respectively.

\section{SPECT/CT imaging}

SPECT/CT scans of PC-3 PIP/flu tumor-bearing mice were obtained at $1 \mathrm{~h}, 4 \mathrm{~h}$, and $24 \mathrm{~h}$ after injection of $\sim 25 \mathrm{MBq}{ }^{161} \mathrm{~Tb}$-PSMA-617, resulting in images that were comparable to those previously obtained with ${ }^{177}$ Lu-PSMA-617 (Fig. 3) [27]. Radioligand accumulation was visualized in the PC-3 PIP tumor xenograft on the right side, while negligible uptake was seen in the PSMA-negative PC-3 flu tumor on the left side. Renal excretion of ${ }^{161} \mathrm{~Tb}-\mathrm{PSMA}-617$ was fast and the activity almost entirely excreted after $4 \mathrm{~h}$.

\section{Preclinical tumor therapy}

Constant tumor growth over time was observed in untreated mice of the control group, resulting in three mice that reached the endpoint at Day 18. The tumor growth of mice treated with 5.0 MBq and $10 \mathrm{MBq}{ }^{161} \mathrm{~Tb}$-PSMA- 
Fig. 1 Results of the PC-3 PIP/flu tumor $(\mathbf{a} / \mathbf{c} / \mathbf{e})$ cell viability and $(\mathbf{b} /$ d/f) survival studies. $\mathbf{a}, \mathbf{b}$ Percentage of PC-3 PIP tumor cell viability and survival using ${ }^{161} \mathrm{~Tb}$ PSMA-617 and ${ }^{177}$ Lu-PSMA617 compared to untreated control cells (set to $100 \%$ viability; average \pm SD). c, d Percentage of PC-3 flu tumor cell viability using ${ }^{161} \mathrm{~Tb}-\mathrm{PSMA}-617$ and ${ }^{177} \mathrm{Lu}$-PSMA-617 compared to untreated control cells (set to $100 \%$ viability; average \pm SD). e, f Percentage of PC-3 PIP tumor cell viability using ${ }^{161} \mathrm{~Tb}$-DTPA and ${ }^{177} \mathrm{Lu}$-DTPA compared to untreated control cells (set to $100 \%$ viability; average \pm SD). * indicates the range where significantly different data was obtained for ${ }^{161}$ Tb-PSMA-617 and ${ }^{177} \mathrm{Lu}-\mathrm{PSMA}-617(p<0.05)$. a

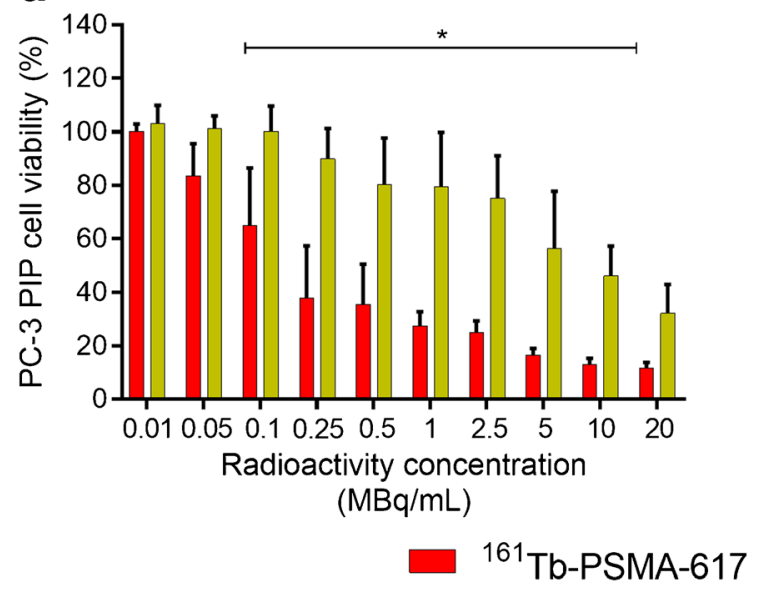

C

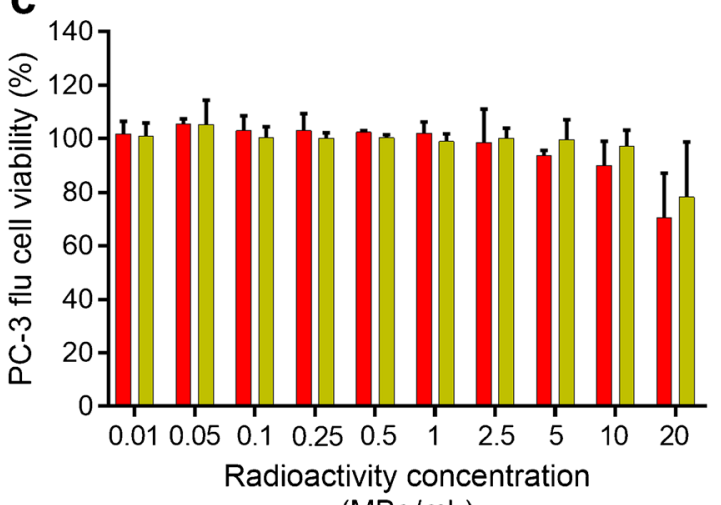

$(\mathrm{MBq} / \mathrm{mL})$

${ }^{161}$ Tb-PSMA-617

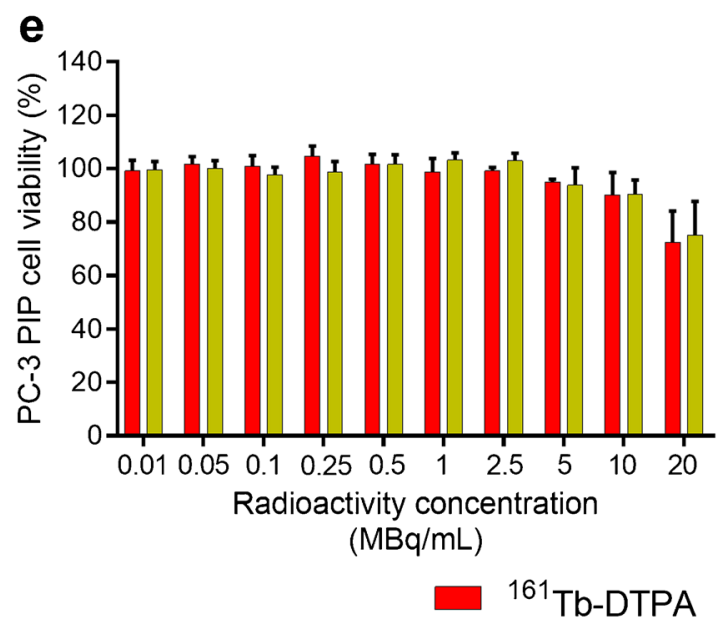

b

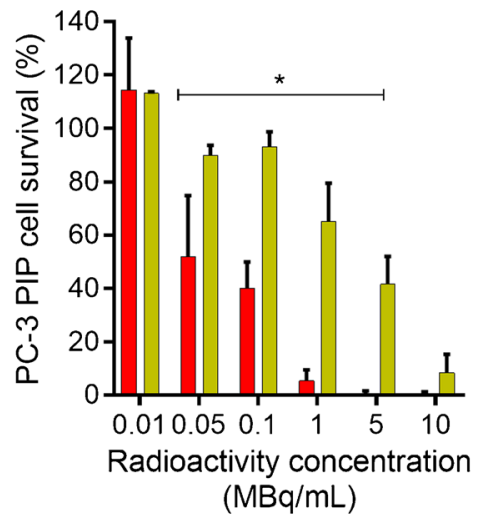

${ }^{177}$ Lu-PSMA-617

d

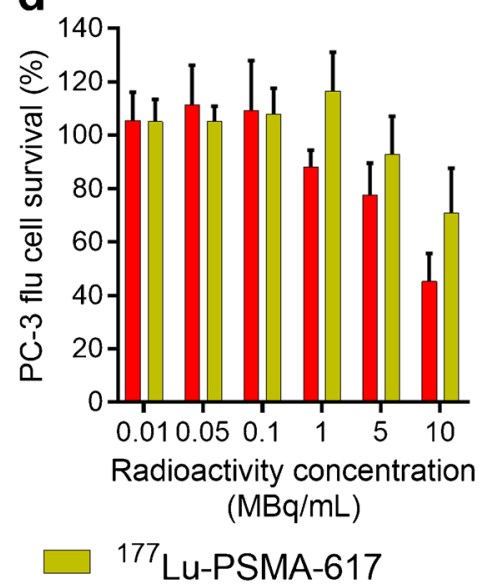

f

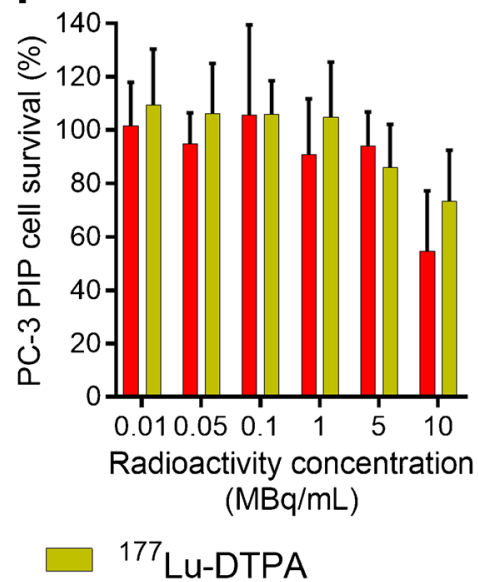

617 was delayed, and hence the first mouse from these groups had to be euthanized at Day 30 and Day 42 respectively. The mice from the group treated with 5.0 $\mathrm{MBq}{ }^{161} \mathrm{~Tb}$-PSMA-617 were terminated when the last mouse of the group reached the endpoint at Day 66 ; however, in the group treated with $10 \mathrm{MBq}{ }^{161} \mathrm{~Tb}-$
PSMA-617, two mice were still alive at the end of the study at Day 84 (Table 2; Fig. 4). The tumor response in mice that received $10 \mathrm{MBq}{ }^{161} \mathrm{~Tb}-\mathrm{PSMA}-617$ was highly variable among the six mice, ranging from similar effects to those observed after injection of $5.0 \mathrm{MBq}{ }^{161} \mathrm{~Tb}-$ PSMA-617 to complete tumor remission (Fig. 5). 
Fig. 2 Biodistribution data of ${ }^{161}$ Tb-PSMA-617 in comparison to ${ }^{177}$ Lu-PSMA-617 in PC-3 PIP/ flu tumor-bearing mice until $96 \mathrm{~h}$ p.i. (average $\pm \mathrm{SD}, \mathrm{n}=3-5$ ). a Uptake in PC-3 PIP tumors (PSMA positive). b Uptake in PC-3 flu tumors (PSMA negative). $\mathbf{c}$ Blood activity levels. d uptake in muscles. e Renal retention and $\mathbf{f}$ uptake in the liver. a

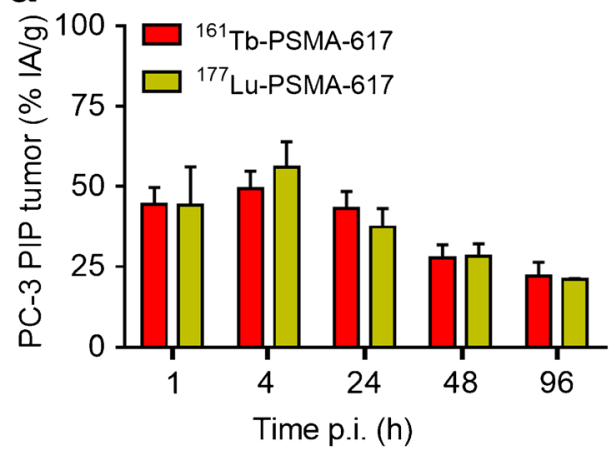

C

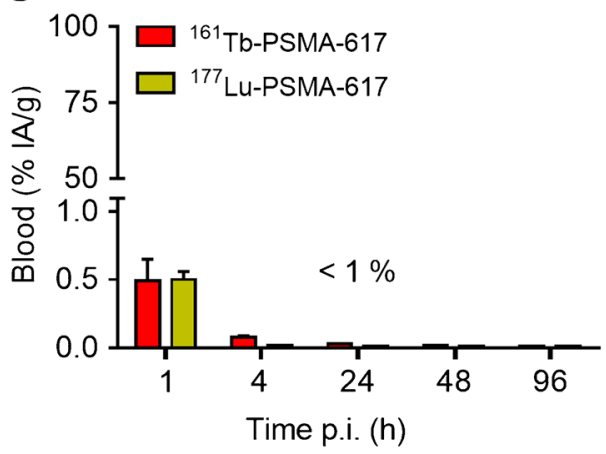

e

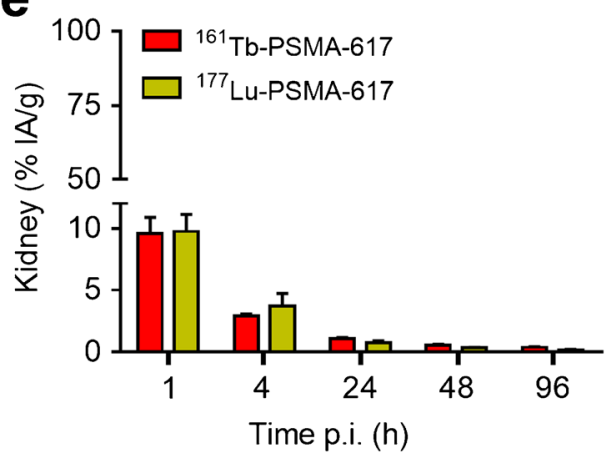

b

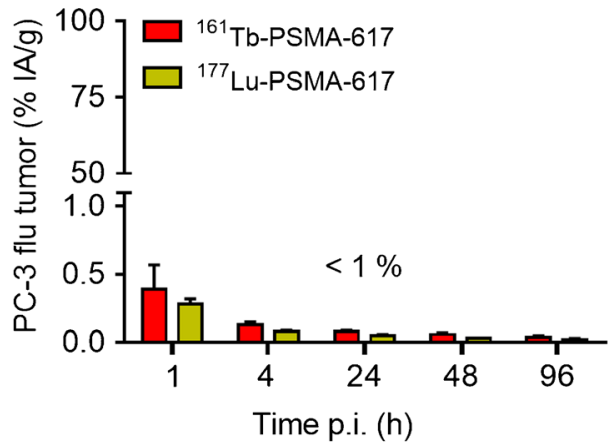

d

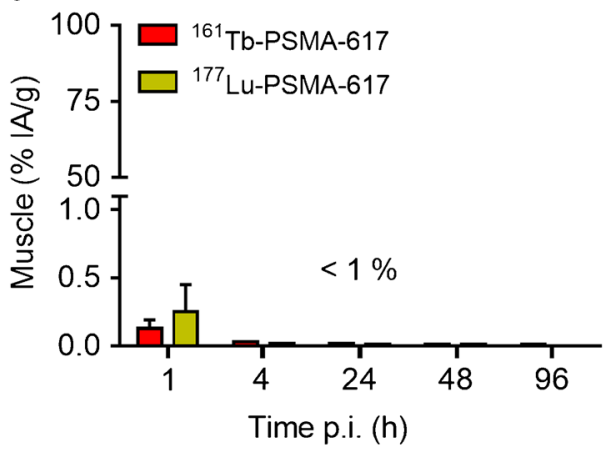

f

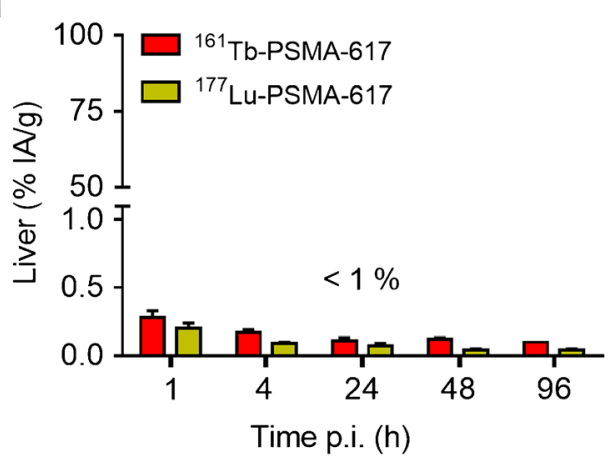

The median survival time of mice treated with ${ }^{161} \mathrm{~Tb}$ PSMA-617 was 36 days, which was clearly longer than the median survival of the control mice (19 days). The application of $10 \mathrm{MBq}{ }^{161} \mathrm{~Tb}$-PSMA-617 increased the median survival of mice to 65 days. In two of the six cases of this group, the PC-3 PIP tumors disappeared entirely, so that the mice survived over 12 weeks without any signs of tumor regrowth (Figs. 4 and 5).

\section{Monitoring of mice during therapy}

In the group of mice that received $10 \mathrm{MBq}{ }^{161} \mathrm{~Tb}$-PSMA-617, the body weight was slightly higher than in the other two groups at therapy start. While control mice and mice that received 5.0 MBq ${ }^{161} \mathrm{~Tb}$-PSMA-617 experienced body weight loss over time, the body weight of mice that received $10 \mathrm{MBq}$
${ }^{161}$ Tb-PSMA-617 remained stable (Supplementary material, Table S3). In line with this result, the average absolute organ mass, calculated for kidney, liver and spleen of these mice, were also higher compared to those recorded in mice from the two other groups. The same held true for these organ masses calculated relative-to-body mass and relative-to-brain mass (Supplementary material, Table S3/S4). This indicates that exposure to ${ }^{161} \mathrm{~Tb}$-PSMA-617 at $10 \mathrm{MBq}$ per mouse mitigated the detrimental effects on the general health status observed in the other groups, which were probably caused by the rapidly growing tumors.

Evaluation of selected clinical chemistry parameters of renal and hepatic function (CRE, BUN ALP, TBIL, ALB) and the histological analysis of the bone marrow and salivary glands revealed no meaningful difference between the different groups (Supplementary material, Tables S5/S6). 
Fig. 3. SPECT/CT images of mice after injection of $\sim 25 \mathrm{MBq}$

${ }^{161}$ Tb-PSMA-617 shown as maximum intensity projections. a Scan obtained 1 h p.i.. b Scan obtained 4 h p.i.. c Scan obtained 24 h p.i.

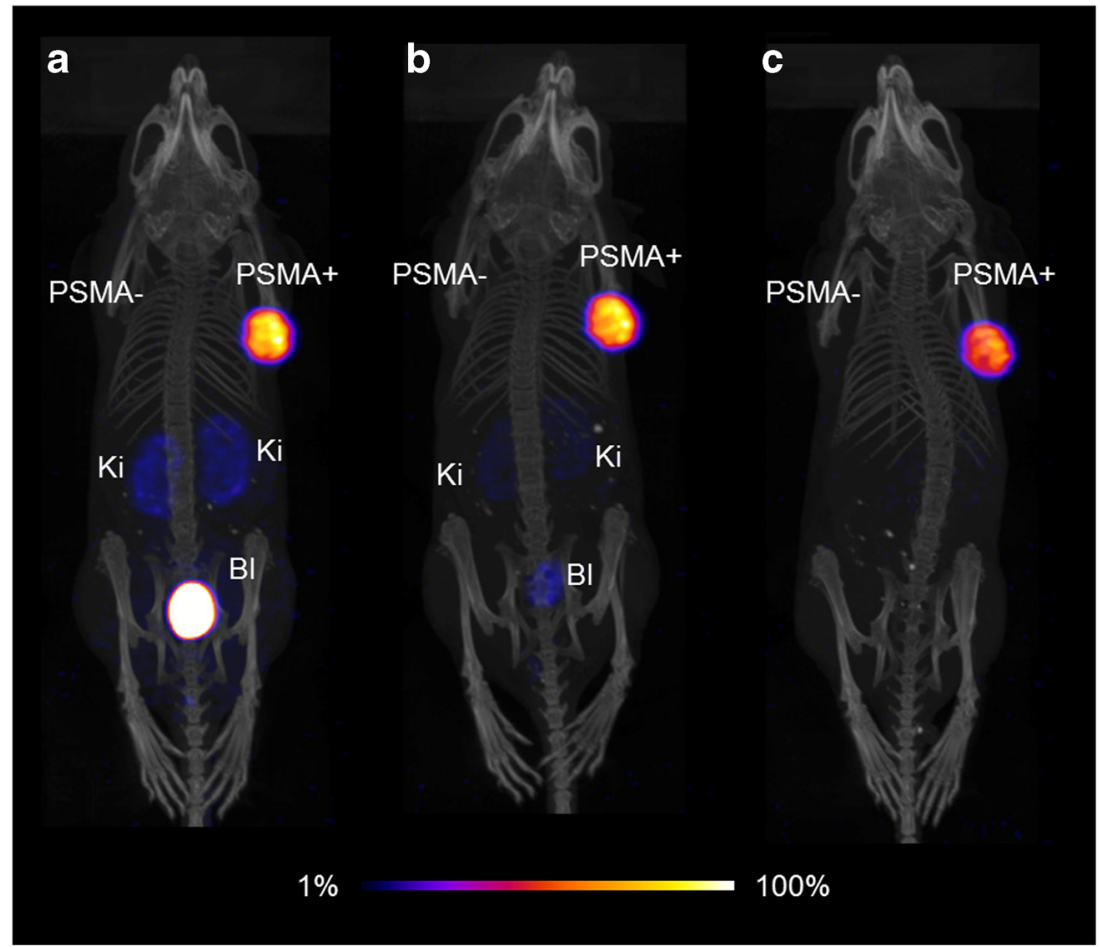

\section{Additional investigations}

A better tumor response to ${ }^{161}$ Tb-PSMA-617 treatment as compared to ${ }^{177} \mathrm{Lu}$-PSMA-617 was demonstrated in additional preclinical studies. In this case, mice received the radioligands already 2 days after PC-3 PIP tumor cell inoculation when the tumor tissue was not yet developed (Supplementary material; Table S7; Fig. S4). There was a clear trend of enhanced tumor growth inhibition and increased survival after application of ${ }^{161}$ Tb-PSMA-617 as compared to ${ }^{177}$ Lu-PSMA-617 at all activity levels (Supplementary material, Fig. S4/S5, Table S8).

\section{Discussion}

In this study, ${ }^{161} \mathrm{~Tb}$ was investigated as a potential alternative to ${ }^{177} \mathrm{Lu}$ to be used in combination with PSMA-targeting ligands. The production of no-carrier-added ${ }^{161} \mathrm{~Tb}$ has been developed to a quality that is comparable to that of no-carrier-added ${ }^{177} \mathrm{Lu}$, enabling efficient radiolabeling of biomolecules under the same experimental conditions. Attempts to label PSMA-617 with ${ }^{161} \mathrm{~Tb}$ at specific activities up to $100 \mathrm{MBq} / \mathrm{nmol}$ resulted in radiochemically pure ${ }^{161}$ Tb-PSMA-617 (> 98\%). The radiolytic degradation of ${ }^{161}$ Tb-PSMA-617 was similar to ${ }^{177}$ Lu-PSMA617, indicating that the emitted conversion and Auger electrons did not play a critical role with regard to the radioligand's stability.

In agreement with previously-performed studies that compared ${ }^{161} \mathrm{~Tb}$ - and ${ }^{177} \mathrm{Lu}$-folate conjugates [29], the in-vitro properties of ${ }^{161}$ Tb-PSMA-617 and ${ }^{177}$ Lu-PSMA-617 were largely the same. This included the $n$-octanol/PBS distribution coefficient and cell uptake and internalization in PSMA-positive and PSMA-negative tumor cells. It was also confirmed that the pharmacokinetics of ${ }^{161}$ Tb-PSMA-617 was equal to ${ }^{177}$ Lu-PSMA617 , resulting in the same biodistribution profiles as expected (Fig. 2). It is likely that these findings can be extrapolated to
Table 2 Various parameters characterizing the efficacy of the treatment

\begin{tabular}{lllllll}
\hline Treatment & $\begin{array}{l}\text { Injected } \\
\text { activity }\end{array}$ & $\begin{array}{l}\text { First mouse } \\
\text { euthanized }\end{array}$ & $\begin{array}{l}\text { Last mouse } \\
\text { euthanized }\end{array}$ & $\begin{array}{l}\text { Median } \\
\text { survival }\end{array}$ & $\mathrm{TGDI}_{2}$ & $\mathrm{TGDI}_{3}$ \\
\hline & $(\mathrm{MBq})$ & $($ Day) & (Day) & (Day) & & \\
Saline & - & 18 & 24 & 19 & $1.0 \pm 0.4$ & $1.0 \pm 0.1$ \\
${ }^{161}$ Tb-PSMA-617 & 5.0 & 30 & 66 & 36 & $4.2 \pm 1.2$ & $2.5 \pm 0.6$ \\
${ }^{161}$ Tb-PSMA-617 & 10 & 42 & $84^{1)}$ & 65 & n.d. & n.d. \\
\hline
\end{tabular}

${ }^{1}$ all mice were euthanized at the end of the study at Day 84 even though 2 mice had not reached an endpoint. 
a

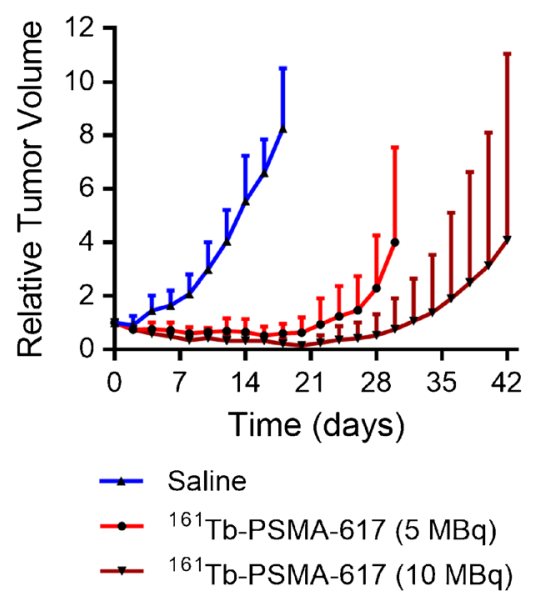

Fig. 4 Graphs representing tumor growth and survival of control mice (blue) and mice treated with ${ }^{161}$ Tb-PSMA-617 (red and dark red) with each group comprising of $n=6$ mice. a Average tumor size shown until the first mouse of each group reached an endpoint; untreated control mice (blue), mice injected with $5.0 \mathrm{MBq}{ }^{161} \mathrm{~Tb}-\mathrm{PSMA}-617$ (red) and mice

any targeting agent with a DOTA-chelator; thus, ${ }^{161} \mathrm{~Tb}$ could replace ${ }^{177} \mathrm{Lu}$ for any given biomolecule without changing its pharmacokinetic profile.

The enhanced therapeutic effects of ${ }^{161} \mathrm{~Tb}$ compared to ${ }^{177} \mathrm{Lu}$ became obvious from in-vitro data where the exposure to ${ }^{161} \mathrm{~Tb}$-PSMA-617 reduced the viability and survival of PC3 PIP tumor cells in an activity-dependent manner. In agreement with dosimetric calculations, ${ }^{161}$ Tb-PSMA-617 was up to 3 -fold more effective than ${ }^{177} \mathrm{Lu}$-PSMA-617 in vitro. This difference in efficacy of ${ }^{161}$ Tb-PSMA-617 and ${ }^{177}$ Lu-PSMA617 was not observed when using PSMA-negative PC-3 flu cells or when PC-3 PIP cells were exposed to the DTPAcomplexes of the two radionuclides. These findings confirmed that the observed advantage of using ${ }^{161}$ Tb-PSMA-617 over ${ }^{177}$ Lu-PSMA-617 is dependent on PSMA binding and internalization. The in-vitro findings also corroborated previous invitro findings, where ${ }^{161} \mathrm{~Tb}$-folate was more effective in reducing KB tumor cell viability than ${ }^{177}$ Lu-folate [29].

The treatment of PC-3 PIP tumor-bearing mice with 5.0 $\mathrm{MBq}$ and $10 \mathrm{MBq}{ }^{161} \mathrm{~Tb}-\mathrm{PSMA}-617$, respectively, showed an activity-dependent tumor growth inhibition and prolonged survival of mice. When ${ }^{161}$ Tb-PSMA-617 was applied at $10 \mathrm{MBq}$, the tumor xenografts disappeared entirely in two out of six mice, which were still alive at study-end after 12 weeks. As no signs of undesired side-effects were detectable, higher activities may be used to treat the tumors more effectively. The tumor growth inhibition and median survival $\left(\mathrm{TGDI}_{2}=4.2 \pm 1.2 ; 36\right.$ days; Table 2$)$ of mice that received 5.0 MBq ${ }^{161} \mathrm{~Tb}$-PSMA-617 indicated better therapy response that that achieved in previously-reported results obtained with $5.0 \mathrm{MBq}{ }^{177} \mathrm{Lu}-\mathrm{PSMA}-617\left(\mathrm{TGDI}_{2}=2.1 \pm 0.3\right.$, median survival: 32 days [34]). Individual mice treated with $5.0 \mathrm{MBq}$
${ }^{161}$ Tb-PSMA-617 revealed a heterogeneous response pattern, where the last mouse reached the endpoint at Day 66. In contrast, the use of ${ }^{177}$ Lu-PSMA-617 therapy resulted in the last mouse to be euthanized at Day 40 [34].

In additional experiments, we simulated the situation of tumor cells in vivo that have not yet grown to a tissue, in order to investigate whether the radioligands delayed the formation of solid tumors (Supplementary material). At that time, a vascularized tissue was not yet developed, and the measurable "swelling" could presumably be ascribed to the formation of a tumor cell cluster. When applied at activities of $2.5 \mathrm{MBq}$, 5.0 MBq, or $10 \mathrm{MBq}$, the effect of ${ }^{161} \mathrm{~Tb}$-PSMA-617 was enhanced when compared to that of ${ }^{177} \mathrm{Lu}-\mathrm{PSMA}-617$, and re-growth of already disappeared tumors was less frequent when using ${ }^{161}$ Tb-PSMA-617 (Supplementary material; Fig. S4; Table S8). These results confirmed the anticipated improved effect of ${ }^{161} \mathrm{~Tb}$ over ${ }^{177} \mathrm{Lu}$ also at the level of single cancer cells or cancer cell clusters in vivo.

In line with these results, the dosimetry analysis revealed that ${ }^{161} \mathrm{~Tb}$ has a 1.4 -fold higher energy deposition in established tumors compared to ${ }^{177} \mathrm{Lu}$. This ratio increases to about 4-fold for small cell clusters and single cells. Together with the biological results obtained in this study, the dosimetry confirms that ${ }^{161} \mathrm{~Tb}$ may be better suited than ${ }^{177} \mathrm{Lu}$ for sterilizing small cell clusters in advanced metastatic prostate cancer with radiolabeled PSMA ligands.

To date, it remains unclear to what extent the design of the targeting ligand could contribute to fully exploiting the decay properties of ${ }^{161} \mathrm{~Tb}$. It has been stated in literature that nuclear localization is necessary to obtain effective Auger electron therapy [35-38]. In the case of ${ }^{161} \mathrm{~Tb}$, the additional effect is, however, given predominantly by the emission of conversion 


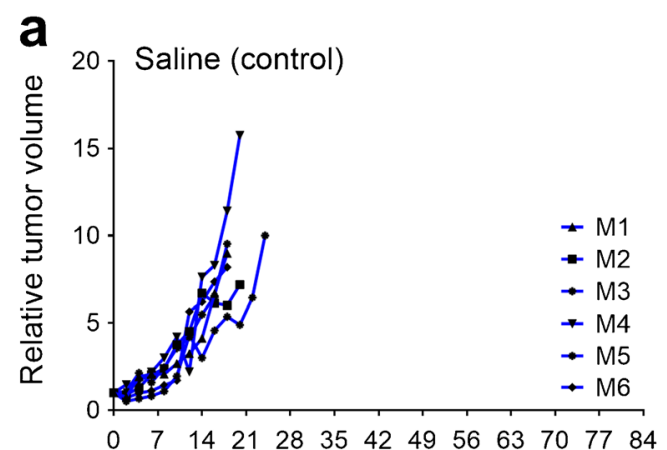

Time (d)

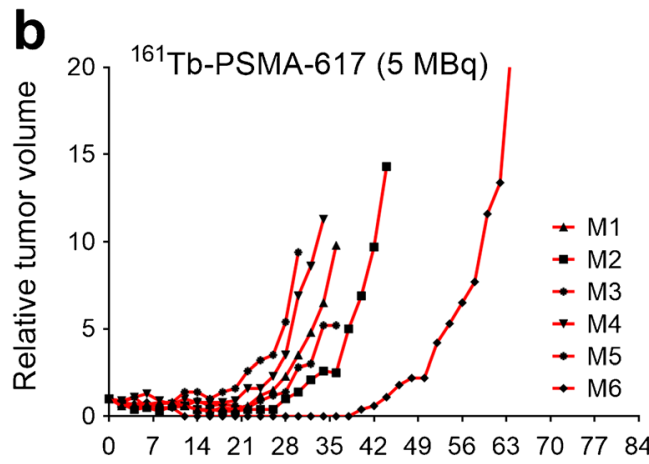

Time (d)

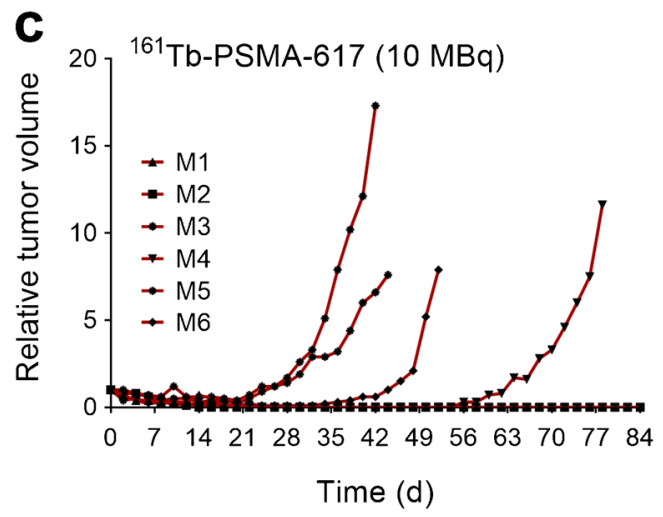

Fig. 5 Graphs representing individual tumor growth of control mice (blue) and mice treated with ${ }^{161}$ Tb-PSMA-617 (red and dark red). a Individual mice injected with saline. b Individual mice treated with ${ }^{161}$ Tb-PSMA-617 (5.0 MBq/mouse). c Individual mice treated with ${ }^{161}$ Tb-PSMA-617 (10 MBq/mouse).

electrons of an energy and tissue range comparable to $\beta^{-}$particles of lowest energy. Hence, even when neglecting Auger electrons, the absorbed dose of ${ }^{161} \mathrm{~Tb}$ is still superior to that of ${ }^{177} \mathrm{Lu}$ due to more emitted electrons per decay. It remains to be investigated whether PSMA ligands, comprising a nuclear localizing signal for effective delivery of the radionuclide to the cell nucleus, would improve the effect of ${ }^{161} \mathrm{~Tb}$ further by also making full use of the emitted Auger electrons. More sophisticated ligand designs and more clinically-relevant mouse models for testing the effects will be the topic of future preclinical studies to obtain answers to these open questions.

\section{Conclusion}

${ }^{161} \mathrm{~Tb}$ was used for the first time with a PSMA ligand, which demonstrated better results than ${ }^{177} \mathrm{Lu}-\mathrm{PSMA}-617$ in vitro and in vivo. Based on these findings, the postulated superiority of ${ }^{161} \mathrm{~Tb}$ over ${ }^{177} \mathrm{Lu}$ was corroborated. Our preclinical research activities will be continued to further investigate ${ }^{161} \mathrm{~Tb}$, as we intend to translate it to clinics and provide prostate cancer patients with an optimized treatment option in the near future.

Acknowledgments The authors thank Susan Cohrs and Fan Sozzi for technical assistance of the in-vitro and in-vivo studies, as well as Roger Hasler, Dr. Pascal Grundler, and Dr. Zeynep Talip for assisting the production of ${ }^{161} \mathrm{~Tb}$ at PSI (Switzerland); they thank Lebogang Sepini for assistance with the target irradiations at Necsa (South Africa), and Jens Hemmingsson for the assistance of dosimetry calculations at the University of Gothenburg (Sweden). The authors thank Dr. Konstantin Zhernosekov, Isotope Technologies Garching (ITG GmbH; Germany) for providing no-carrier-added ${ }^{177} \mathrm{Lu}$. Viviane Tschan was funded by the Personalized Health and Related Technologies (PHRT) program of ETH Zurich, Switzerland. Nadezda Gracheva was funded by the Swiss National Science Foundation (IZLIZ3_156800). The production of ${ }^{161} \mathrm{~Tb}$ was supported by the NET Research Foundation Petersen Investigator Award 2018 USA.

\section{Compliance with ethical standards}

Ethical approval This study was performed in agreement with the national law and PSI-internal guidelines of radiation safety protection. Invivo experiments were approved by the local veterinarian department and ethics committee and conducted in accordance with the Swiss law of animal protection.

Conflicts of interest The authors declare no conflict of interest.

Open Access This article is distributed under the terms of the Creative Commons Attribution 4.0 International License (http:// creativecommons.org/licenses/by/4.0/), which permits unrestricted use, distribution, and reproduction in any medium, provided you give appropriate credit to the original author(s) and the source, provide a link to the Creative Commons license, and indicate if changes were made.

\section{References}

1. Silver DA, Pellicer I, Fair WR, Heston WD, Cordon-Cardo C. Prostate-specific membrane antigen expression in normal and malignant human tissues. Clin Cancer Res. 1997;3:81-5.

2. Sweat SD, Pacelli A, Murphy GP, Bostwick DG. Prostate-specific membrane antigen expression is greatest in prostate adenocarcinoma and lymph node metastases. Urology. 1998;52:637-40.

3. Ross JS, Sheehan CE, Fisher HA, Kaufman RP Jr, Kaur P, Gray K, et al. Correlation of primary tumor prostate-specific membrane antigen expression with disease recurrence in prostate cancer. Clin Cancer Res. 2003;9:6357-62.

4. Perner S, Hofer MD, Kim R, Shah RB, Li H, Moller P, et al. Prostate-specific membrane antigen expression as a predictor of prostate cancer progression. Hum Pathol. 2007;38:696-701. https://doi.org/10.1016/j.humpath.2006.11.012. 
5. Afshar-Oromieh A, Babich JW, Kratochwil C, Giesel FL, Eisenhut M, Kopka K, et al. The rise of PSMA ligands for diagnosis and therapy of prostate cancer. J Nucl Med. 2016;57:79S-89S. https:// doi.org/10.2967/jnumed.115.170720.

6. Haberkorn U, Eder M, Kopka K, Babich JW, Eisenhut M. New strategies in prostate cancer: prostate-specific membrane antigen (PSMA) ligands for diagnosis and therapy. Clin Cancer Res. 2016;22:9-15. https://doi.org/10.1158/1078-0432.CCR-15-0820.

7. Rahbar K, Ahmadzadehfar H, Kratochwil C, Haberkorn U, Schafers M, Essler M, et al. German multicenter study investigating ${ }^{177} \mathrm{Lu}-\mathrm{PSMA}-617$ radioligand therapy in advanced prostate cancer patients. J Nucl Med. 2017;58:85-90. https://doi.org/10.2967/ jnumed.116.183194.

8. Eiber M, Fendler WP, Rowe SP, Calais J, Hofman MS, Maurer T, et al. Prostate-specific membrane antigen ligands for imaging and therapy. J Nucl Med. 2017;58:67S-76S. https://doi.org/10.2967/ jnumed.116.186767.

9. Kopka K, Benesova M, Barinka C, Haberkorn U, Babich J. Gluureido-based inhibitors of prostate-specific membrane antigen: lessons learned during the development of a novel class of lowmolecular-weight theranostic radiotracers. J Nucl Med. 2017;58: 17S-26S. https://doi.org/10.2967/jnumed.116.186775.

10. Zechmann CM, Afshar-Oromieh A, Armor T, Stubbs JB, Mier W, Hadaschik B, et al. Radiation dosimetry and first therapy results with a ${ }^{124} \mathrm{I} /{ }^{131}$ I-labeled small molecule (MIP-1095) targeting PSMA for prostate cancer therapy. Eur J Nucl Med Mol Imaging. 2014;41:1280-92. https://doi.org/10.1007/s00259-014-2713-y.

11. Bouchelouche K, Turkbey B, Choyke PL. PSMA PET and radionuclide therapy in prostate cancer. Semin Nucl Med. 2016;46:52235. https://doi.org/10.1053/j.semnuclmed.2016.07.006.

12. Heck MM, Retz M, D'Alessandria C, Rauscher I, Scheidhauer K, Maurer T, et al. Systemic radioligand therapy with ${ }^{177} \mathrm{Lu}$ labeled prostate specific membrane antigen ligand for imaging and therapy in patients with metastatic castration resistant prostate cancer. $\mathrm{J}$ Urol. 2016;196:382-91. https://doi.org/10.1016/j.juro.2016.02. 2969.

13. Kulkarni HR, Singh A, Schuchardt C, Niepsch K, Sayeg M, Leshch $\mathrm{Y}$, et al. PSMA-based radioligand therapy for metastatic castrationresistant prostate cancer: the Bad Berka experience since 2013. J Nucl Med. 2016;57:97S-104S. https://doi.org/10.2967/jnumed. 115.170167.

14. Banerjee S, Pillai MR, Knapp FF. Lutetium-177 therapeutic radiopharmaceuticals: linking chemistry, radiochemistry, and practical applications. Chem Rev. 2015;115:2934-74. https://doi.org/10. 1021/cr500171e

15. Kratochwil C, Bruchertseifer F, Giesel FL, Weis M, Verburg FA, Mottaghy F, et al. ${ }^{225}$ Ac-PSMA-617 for PSMA-targeted alpha-radiation therapy of metastatic castration-resistant prostate cancer. $\mathrm{J}$ Nucl Med. 2016;57:1941-4. https://doi.org/10.2967/jnumed.116. 178673.

16. Kratochwil C, Bruchertseifer F, Rathke H, Bronzel M, Apostolidis $\mathrm{C}$, Weichert $\mathrm{W}$, et al. Targeted a-therapy of metastatic castrationresistant prostate cancer with ${ }^{225}$ Ac-PSMA-617: dosimetry estimate and empiric dose finding. J Nucl Med. 2017;58:1624-31. https:// doi.org/10.2967/jnumed.117.191395.

17. Kratochwil C, Bruchertseifer F, Rathke H, Hohenfellner M, Giesel FL, Haberkorn U, et al. Targeted alpha-therapy of metastatic castration-resistant prostate cancer with ${ }^{225}$ Ac-PSMA-617: swimmer-plot analysis suggests efficacy regarding duration of tumor control. J Nucl Med. 2018;59:795-802. https://doi.org/10. 2967/jnumed.117.203539.

18. Robertson AK, Ramogida CF, Schaffer P, Radchenko V. Development of ${ }^{225} \mathrm{Ac}$ radiopharmaceuticals: TRIUMF perspectives and experiences. Curr Radiopharm. 2018;11(3):156-72. https://doi.org/10.2174/1874471011666180416161908.
19. Lehenberger S, Barkhausen C, Cohrs S, Fischer E, Grünberg J, Hohn A, et al. The low-energy $\beta^{-}$and electron emitter ${ }^{161} \mathrm{~Tb}$ as an alternative to ${ }^{177} \mathrm{Lu}$ for targeted radionuclide therapy. Nucl Med Biol. 2011;38:917-24. https://doi.org/10.1016/j.nucmedbio.2011. 02.007 .

20. Uusijärvi H, Bernhardt P, Rösch F, Mäcke HR. Forssell-Aronsson E. Electron- and positron-emitting radiolanthanides for therapy: aspects of dosimetry and production. J Nucl Med. 2006;47:807-14.

21. Hindie E, Zanotti-Fregonara P, Quinto MA, Morgat C, Champion C. Dose Deposits from ${ }^{90} \mathrm{Y},{ }^{177} \mathrm{Lu},{ }^{111} \mathrm{In}$, and ${ }^{161} \mathrm{~Tb}$ in micrometastases of various sizes: implications for radiopharmaceutical therapy. J Nucl Med. 2016;57:759-64. https://doi.org/10.2967/ jnumed.115.170423.

22. Müller C, Zhernosekov K, Köster U, Johnston K, Dorrer H, Hohn A, et al. A unique matched quadruplet of terbium radioisotopes for PET and SPECT and for $\alpha$ - and $\beta^{-}$-radionuclide therapy: An in vivo proof-of-concept study with a new receptor-targeted folate derivative. J Nucl Med. 2012;53:1951-9. https://doi.org/10.2967/ jnumed.112.107540.

23. Müller C, Fischer E, Behe M, Köster U, Dorrer H, Reber J, et al. Future prospects for SPECT imaging using the radiolanthanide terbium-155 - production and preclinical evaluation in tumorbearing mice. Nucl Med Biol. 2014;41:e58-65. https://doi.org/10. 1016/j.nucmedbio.2013.11.002.

24. Müller C, Vermeulen C, Johnston K, Köster U, Schmid R, Türler A, et al. Preclinical in vivo application of ${ }^{152} \mathrm{~Tb}$-DOTANOC: a radiolanthanide for PET imaging. EJNMMI Res. 2016;6:35. https://doi.org/10.1186/s13550-016-0189-4.

25. Baum RP, Singh A, Benesova M, Vermeulen C, Gnesin S, Köster $\mathrm{U}$, et al. Clinical evaluation of the radiolanthanide terbium-152: first-in-human PET/CT with ${ }^{152} \mathrm{~Tb}$-DOTATOC. Dalton Trans. 2017;46:14638-46. https://doi.org/10.1039/c7dt01936j.

26. Champion C, Quinto MA, Morgat C, Zanotti-Fregonara P, Hindie E. Comparison between three promising $\beta^{-}$-emitting radionuclides, ${ }^{67} \mathrm{Cu},{ }^{47} \mathrm{Sc}$ and ${ }^{161} \mathrm{~Tb}$, with emphasis on doses delivered to minimal residual disease. Theranostics. 2016;6:1611-8. https://doi.org/10. 7150/thno.15132.

27. Benesova M, Umbricht CA, Schibli R, Müller C. Albumin-binding PSMA ligands: optimization of the tissue distribution profile. Mol Pharm. 2018;15:934-46. https://doi.org/10.1021/acs. molpharmaceut.7b00877.

28. Mosmann T. Rapid colorimetric assay for cellular growth and survival: application to proliferation and cytotoxicity assays. $\mathrm{J}$ Immunol Methods. 1983;65:55-63.

29. Müller C, Reber J, Haller S, Dorrer H, Bernhardt P, Zhernosekov K, et al. Direct in vitro and in vivo comparison of ${ }^{161} \mathrm{~Tb}$ and ${ }^{177} \mathrm{Lu}$ using a tumour-targeting folate conjugate. Eur J Nucl Med Mol Imaging. 2014;41:476-85. https://doi.org/10.1007/s00259-0132563-z.

30. Franken NA, Rodermond HM, Stap J, Haveman J, van Bree C. Clonogenic assay of cells in vitro. Nat Protoc. 2006;1:2315-9. https://doi.org/10.1038/nprot.2006.339.

31. Reber J, Haller S, Leamon CP, Müller C. ${ }^{177}$ Lu-EC0800 combined with the antifolate pemetrexed: preclinical pilot study of folate receptor targeted radionuclide tumor therapy. Mol Cancer Ther. 2013;12:2436-45. https://doi.org/10.1158/1535-7163.MCT-130422-T.

32. Umbricht CA, Benesova M, Schmid RM, Türler A, Schibli R, van der Meulen NP, et al. ${ }^{44} \mathrm{Sc}$-PSMA-617 for radiotheragnostics in tandem with ${ }^{177}$ Lu-PSMA-617-preclinical investigations in comparison with ${ }^{68} \mathrm{Ga}-\mathrm{PSMA}-11$ and ${ }^{68} \mathrm{Ga}-\mathrm{PSMA}-617$. EJNMMI Res. 2017;7:9. https://doi.org/10.1186/s13550-017-0257-4.

33. Salvat F. PENELOPE2014: A code system for Monte-Carlo simulation of electron and photon transport. OECD/NEA Data Bank NEA/NSC/DOC. 2015;3:http://www.nea.fr/lists/penelope.html. 
34. Umbricht CA, Benesova M, Schibli R, Müller C. Preclinical development of novel PSMA-targeting radioligands: modulation of albumin-binding properties to improve prostate cancer therapy. Mol Pharm. 2018;15:2297-306. https://doi.org/10.1021/acs. molpharmaceut.8b00152.

35. Ginj M, Hinni K, Tschumi S, Schulz S, Mäcke HR. Trifunctional somatostatin-based derivatives designed for targeted radiotherapy using Auger electron emitters. J Nucl Med. 2005;46:2097-103.

36. Cornelissen B, Vallis KA. Targeting the nucleus: an overview of Auger-electron radionuclide therapy. Curr Drug Discov Technol. 2010;7:263-79.

37. Costantini DL, McLarty K, Lee H, Done SJ, Vallis KA, Reilly RM. Antitumor effects and normal-tissue toxicity of ${ }^{111}$ In-nuclear localization sequence-trastuzumab in athymic mice bearing HERpositive human breast cancer xenografts. J Nucl Med. 2010;51: 1084-91. https://doi.org/10.2967/jnumed.109.072389.

38. Chen P, Wang J, Hope K, Jin L, Dick J, Cameron R, et al. Nuclear localizing sequences promote nuclear translocation and enhance the radiotoxicity of the anti-CD33 monoclonal antibody HuM195 labeled with ${ }^{111}$ In in human myeloid leukemia cells. J Nucl Med. 2006;47:827-36.

Publisher's note Springer Nature remains neutral with regard to jurisdictional claims in published maps and institutional affiliations. 